\title{
DEVELOPMENT OF PARASITEMIA AND ANEMIA CAUSED BY T.ORIENTALIS INFECTION IN EXPERIMENTAL CALVES
}

\author{
Ts.Alimaa ${ }^{1 *}$, M.Zolzaya $^{1}$, Yoshio Nakamura ${ }^{2}$ \\ ${ }^{1}$ Institute of Veterinary Medicine, Mongolian State University of Life Sciences, \\ Ulaanbaatar, Mongolia \\ ${ }^{2}$ National Institute of Animal Health, Tsukuba, Japan \\ ${ }^{*}$ Corresponding author: amia11mn@yahoo.com
}

\begin{abstract}
In the present study, we have studied development of parasitemia and anemia which caused by T. orientalis infection in experimental calves using different kind of laboratory tests such us blood smear test, blood cell examination test and conventional PCR. The blood smear test is still one of easiest, effective diagnostic methods. According to our results the sensitivity of this test was as same as PCR.
\end{abstract}

KEY WORDS: Theileriosis, blood smear, PCR

\section{INTRODUCTION}

Theileriae are obligate intracellular protozoan parasites belonging to the phylum Apicomplexa that infect both wild and domestic Bovidae throughout much of the world (some species also infect small ruminants). They are transmitted by Ixodid ticks, and have complex life cycles in both vertebrate and in vertebrate hosts. When ticks carrying Theileria feed on cattle, the parasite gets into their bloodstream and enters red blood cells. In some animals sufficient red blood cells are destroyed to cause anemia-a reduction in the red blood cell numbers. This reduces the ability of blood to carry oxygen and makes the animal ill. Beningn Theileria parasites are distributed all over the world [3]. Anemia is considered as a decrease in red blood cells (RBC), hemoglobin $(\mathrm{Hb})$ and packed cell volume (PCV) in the blood stream [4]. Generally, detection of $T$. orientalis parasites in Giemsa stained thin blood smear films by means of microscopy. However, diagnosis of $T$. orientalis infection is very difficult asymptomic or chronic infections since the parasitimea level is very low in addition, Bovine Theileriosis is caused by Theileria orientalis which are widely distributed in many Asia-Pacific countries, and is sometimes responsible for serious economic losses in the livestock industry can subsequently arise. The major piroplasm surface protein (MPSP), a conserved protein in all theileria species, has been used as a marker for epidemiological and phylogenetical studies of benign Theileria species [1]. MSPC PCR was reported by Ota et al., [2] as a diagnostic method targeting $T$. orientalis infections. This study is conducting on cattle in the animal house of National Institute of Animal Health, Japan. Study was carried out between 14 May to 21 October, 2013. The purpose of the present study was to investigate development of parasitemia and anemia which caused by $T$. orientalis infection in experimental cattle. The specific objectives were to compare the changes in blood component of calves before and after their inoculation with $T$. orientalis.

\section{MATERIALS AND METHODS}

Initially, a study was commenced on six (6) calves which were clinically healthy. The calves were
Holstein, about 5 months old at the time of exposure. They were ensured free from hemoparasite infection 
by PCR. The splenectomy was done in all calves, after 1 month observation.

Chronic infection (low dose infection). A month later of the splenectomy, the animals with IDs 8003, 8004,8005 and 8006 inoculated by T. orientalis Ikeda stock infected blood from No.16 animal on June 20, 1985 (approximately $1 \times 10^{9}$ infected red blood cells) each $9 \mathrm{ml}$. Used parasitized RBC with Alsever's solution ( $20 \%$ glycerol) was stored in liquid nitrogen container since 1985 years. Two out of six calves $(8001 ; 8002)$ were control animals.

Acute infection (high dose infection). For the second time two calves (IDs 8001 and 8002) were inoculated of $15 \mathrm{ml}$ blood infected with $T$. orientalis which are taken from initially infected number 8004 calve subcutaneously on 3, September.

\section{Blood collection}

In all calves, blood sampling was done weekly from jugular veins under aseptic conditions in each 2 tubes respectively, before and after infection by following;

a. Approximately $2 \mathrm{ml}$ of blood collected in ethylenediaminetetetraacetic acid (EDTA) containing tubes are used for blood smear, whole blood cell counting and PCR assay. The blood samples for PCR assay were stored at $-20^{\circ} \mathrm{C}$ until use.

b. Another $10 \mathrm{ml}$ blood were collected in blood collection tube and used for serum separation. Serum was separated in each collection by centrifugation at $2000 \mathrm{rpm}$ for 10 minute, and then stored at $-20^{\circ} \mathrm{C}$, for further study such as microscopic examination, ELISA test and PCR assay.

\section{Blood sample analysis}

Hematocrit values (HCT), red blood cell (RBC) were measured in all collected blood samples by a blood analyzer machine (Celltac $\alpha$, MEK-6450; Nihon Kohden ${ }^{\circledR}$, Tokyo, Japan).

\section{Detection of $\boldsymbol{T}$. orientalis parasitemia}

Thin blood smears were prepared and numbered immediately after taking blood samples with EDTA and marked. In the laboratory blood smears were fixed in methanol for 2 minutes and stained for 30 min in Geimsa stain diluted with $5 \%$ phosphate buffer for 1 hour. Slides were examined for detection of parasite Theileria at 100x objective magnification on a Nikon microscope. The smears were recorded as negative for Theleiria if no parasites were detected in 50 oil immersion fields.

\section{DNA extraction and conventional PCR}

1. DNA extraction. DNA was extracted from $200 \mu 1$ of blood sample using QIAamp ${ }^{\circledR}$ DNA Blood Mini Kit (Qiagen, Hilden, Germany) and $200 \mu 1$ of the DNA obtained and stored at $-20^{\circ} \mathrm{C}$ until use.

2. Conventional PCR. In present study, we used a pair of primers for the PCR identification of $T$. orientalis. The primer pair (Table 1) was targeted to the gene encoding the major surface protein-MPSP and was able to amplify the indicated sizes of DNA fragments by PCR.

\section{Primers used for conventional PCR}

Table 1.

\begin{tabular}{ccccc}
\hline Parasite & $\begin{array}{c}\text { Primer } \\
\text { name }\end{array}$ & $\begin{array}{c}\text { Target } \\
\text { sequence }\end{array}$ & Sequence (5-3) & Reference \\
\hline $\begin{array}{c}\text { Theileria } \\
\text { orientalis }\end{array}$ & $\begin{array}{c}\text { MPSP-F } \\
\text { MPSP-R }\end{array}$ & $776 \mathrm{bp}$ & $\begin{array}{c}\text { CTTTGCCTAGGATACTTCCT } \\
\text { ACGGCAAGTGGTGAGAACT }\end{array}$ & $\begin{array}{c}\text { Ota et al., } \\
2009\end{array}$ \\
\hline
\end{tabular}

This PCR analyze was performed $1 \mu l$ of stored DNA template extracted from blood sample, mixed with 5 $\mu 1$ of reaction buffer, consisting of $0.2 \mu 1 \mathrm{Ex}$ Taq DNA polymerase (Takara, Tokyo, Japan), $1 \mu \mathrm{l}$ of each primer and $37.75 \mu 1$ double distilled water. These reactions were performed using an Cycler Thermal Cycler (Gene Amp PCR System 9700).

PCR condition: All the PCR reactions were conducted in a $50 \mu 1$ reaction volume.
The final thermal cycling program included an initial 5 min denaturation at $94^{\circ} \mathrm{C}$ and then 35 cycles of 1 sec at $94^{\circ} \mathrm{C}, 1 \mathrm{~min}$ at $58^{\circ} \mathrm{C}$, and $2 \mathrm{~min}$ at $72^{\circ} \mathrm{C}$, followed by a final extension for $15 \mathrm{~min}$ at $72^{\circ} \mathrm{C} .10$ $\mu 1$ of PCR products were separated by electrophoresis in $15 \mathrm{~g} / 1$ agarose in TAE. The gels were stained with ethiduim bromide for examination under UV light. 


\section{A splenectomy:}

For a splenectomy, calves were general anesthetized with $2 \mathrm{ml}$ pentobarbital $(0.1 \mathrm{mg} / \mathrm{mL})$ and $2 \mathrm{ml}$ xylazine $(0.1 \mathrm{mg} / \mathrm{mL})$. Approximately $15 \mathrm{~cm}$ incision was performed and the spleen was removed. The incision was sutured and animals were monitored until their consciousness.

\section{RESULT AND DISCUSSION}

We have done the surgery for removal of the spleen from 6 experimental calves successfully. After surgery, all calves showed no clinical sings of inflammation. A month later of the splenectomy, the smears $(\mathrm{n}=144)$ were recorded as negative for Theleiria, no parasites were detected in 50x oil

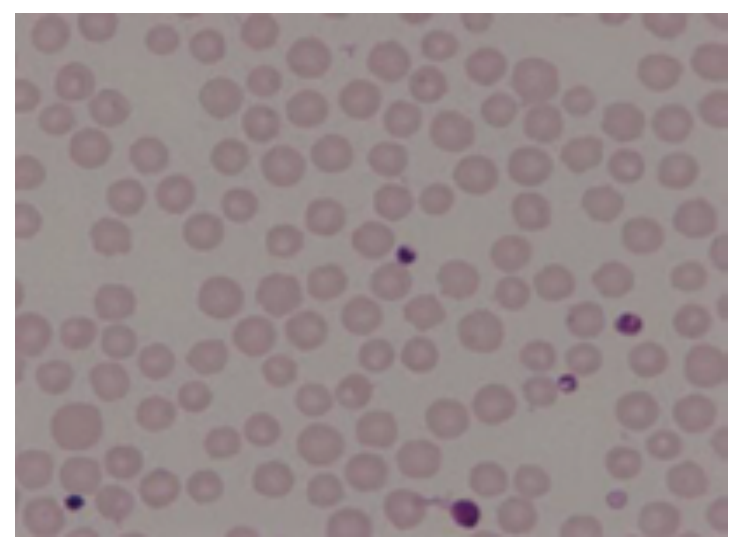

Figure 1. Calf blood smears showing negative for Theileria parasites.

Giesa staining $(\mathrm{x} 400)$.

$\boldsymbol{R} \boldsymbol{B C}$ counting RBC counts were decreased from 2 up to 12 weeks and day 7 after inoculation with low dose and high dose of Theileria parasites, respectively. For the chronic infection, the peak of anemia occurred

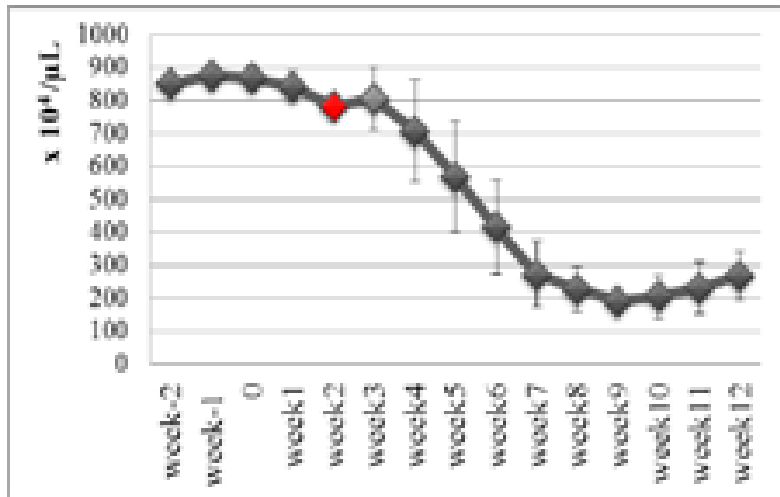

Figure 3. RBC count in chronic infection (Data are means $\pm \operatorname{SD}(n=4)\left({ }^{*} p<0.05\right)$

\section{Comparison of assays and statistical analysis}

Some parameters of hematology and biochemistry before and after surgery were compared by T-test. The sensitivity of detection of Theilerias on smears and by PCR was compared all samples.

immersion fields in all samples before the parasite inoculation (Figure 1). Then parasites were first detected in blood film on 14 dpi of animals given a low dose parasites and 3 days in the animal given a high dose infection (Figure 2).

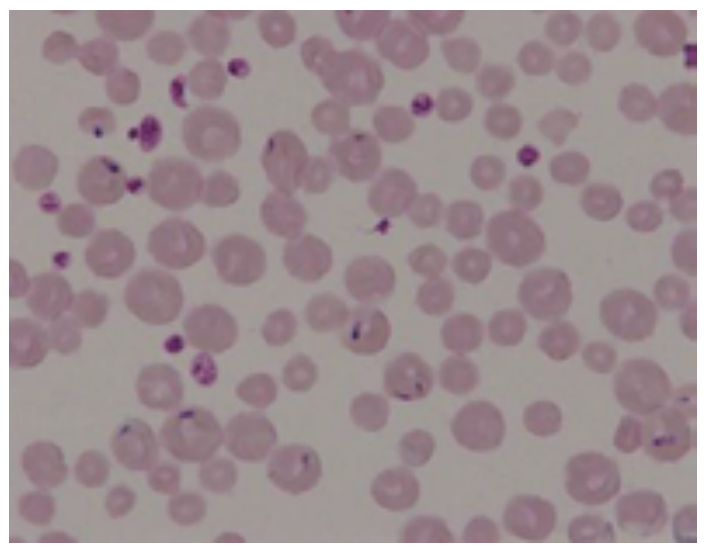

Figure 2. Calf blood smears showing intraerythrocytic form of Theileria parasites. Giesa staining (x400).

at mean of 9 weeks, whereas the peak of anemia occurred at mean of 40 days $\left(\mathrm{RBC}-200 \times 10^{4} / \mu \mathrm{l}\right)$ in acute infection.

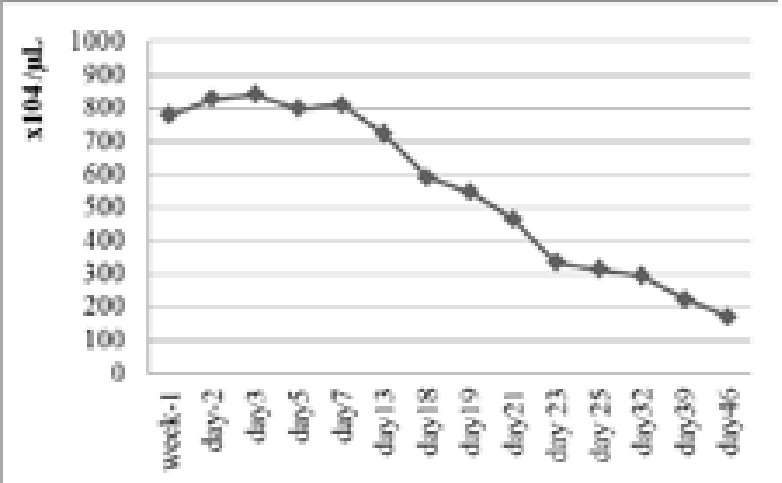

Figure 4. RBC count in acute infection

(Data are means $\pm \mathrm{SD}(\mathrm{n}=2)$ 
From the figure showed that the peak of anemia occurs at mean of 9 weeks after inoculation with Theileria parasites. The delayed of anemia occurrence may be due to usage of long storage frozen blood parasites which age about 28 years old, which may reduce the titer of parasites. Second point due to low concentration of inoculation where for these experiments we use $1 \times 10^{9}$ concentrated inoculums to test on these animals. Third point these animals may still have maternal antibodies that keep then to combat the pathogens well for 1st week until 7 weeks post inoculation.Other two calves (acute infection) were used and indicated with blood of calf (animal ID: 8004) which showed peak of anemia occurrence at 40 days post infection (dpi). It indicated that the anemia started approximately at 5 th days post inoculation in both calves where the result showed declined of RBC counts until 46th days which indicated lowest RBC counts. The lowest RBC count occurred at 40 dpi were similar to previous development of anemia started approximately between 9 weeks post inoculation, where the

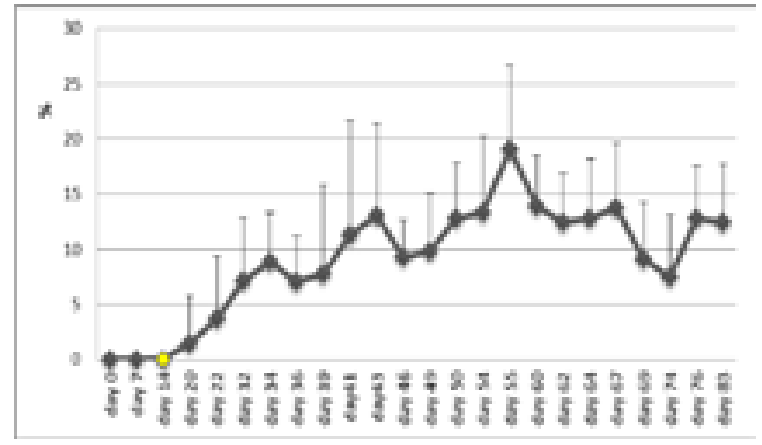

Figure 5. Parasitemia (\%) in chronic infection (Data are means $\pm \mathrm{SD}(\mathrm{n}=4)$

Hematocrit values (HCT) Anemia showing an HCT less than 25\% was developed from 4-6 weeks and 10 days after infection with low dose and high dose of

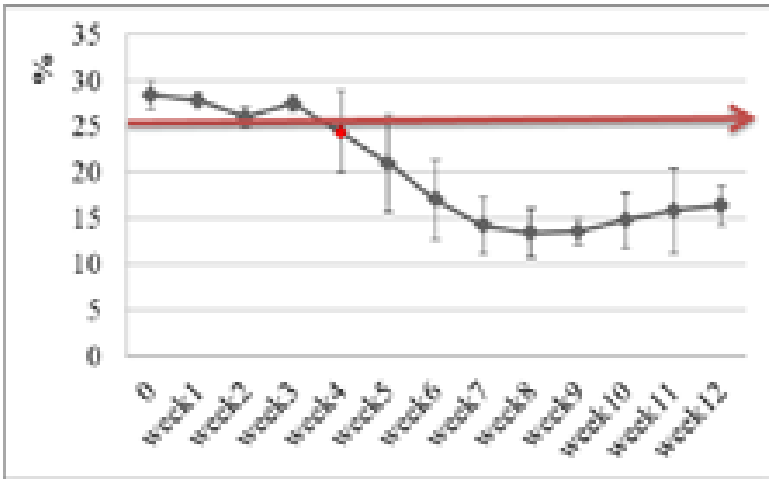

Figure 7. HCT in chronic infection

(Data are means $\pm \mathrm{SD}(\mathrm{n}=4)$ development of anemia. These phenomena started at 1st week post inoculation may due to 3 points; a). Usage of fresh blood parasite which may contain high titer of blood parasite, b). High concentrated of blood parasite given to calves were 3 times higher than first experiment c). Maternal antibodies in both calves were not sufficient to combat the higher volume of blood parasite. This cause the immunity failed to develop due to the lysis of RBC in the body.

Parasitemia The occurrence percentage of parasitemia in chronic infection started at $14 \mathrm{dpi}$ and increased until 55 dpi (TS-P 2.21\%-20.0\%), then declined till 74 dpi (Figure 5) and no declination occurred from $76^{\text {th }}$ days till end of experiment. Whereas, Theileria parasites were first detected at 3 th days in the animal given a high dose infection (Figure $6)$. The two peak of parasitemia (20\%) may indicated that the body immune system try to combat the infection and parasite released in blood in high volume at 55 and $19 \mathrm{dpi}$ in chronic and acute infection.

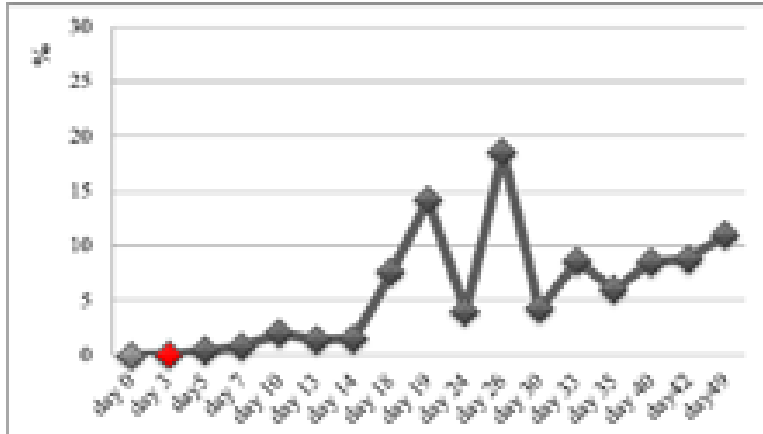

Figure 6. Parasitemia (\%) in acute infection (Data are means $\pm \mathrm{SD}(\mathrm{n}=2)$

Theileria parasites, respectively (Figure 4 and 5). High rate anemia was $13.3 \%$ in 8 weeks after parasites inoculation.

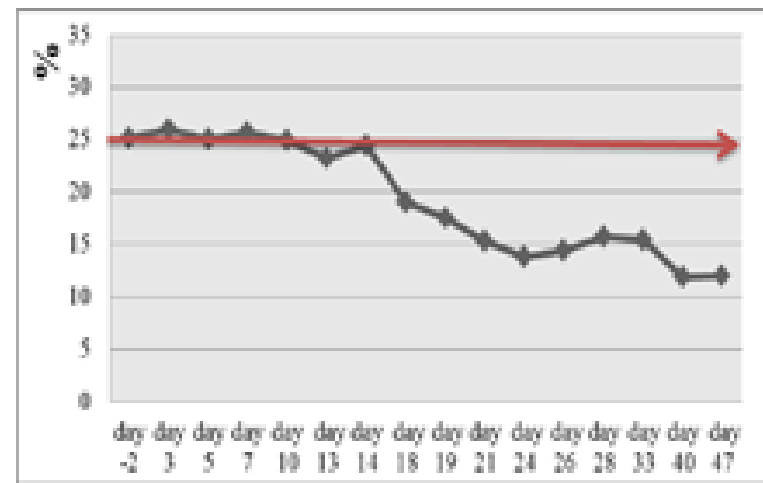

Figure 8. HCT in acute infection

(Data are means \pm SD $(n=2)$ 


\section{PCR assay}

We examined specific DNA parts by PCR and used specific primers for screening of the major piroplasm

shown in figure 9 indicated that the template DNA of surface protein (MPSP). The result of PCR assay is lane 1-6 showed all negative to T. orientalis before the parasite inoculation

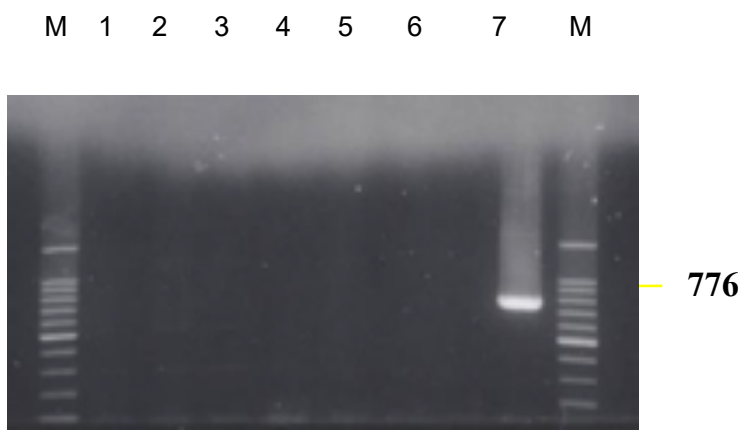

Figure 9. Detection of conventional PCR bands $776 \mathrm{bp}$ represented the amplification of target gene MPSP. M, ladders of DNA Marker (1kb); 2-7 templates

The chronic infection: The amplification of target gene MPSP from $T$. orientalis was detected in calves (IDs 8003, 8004, 8005 and 8006) at 14, 7, 16, 7 days

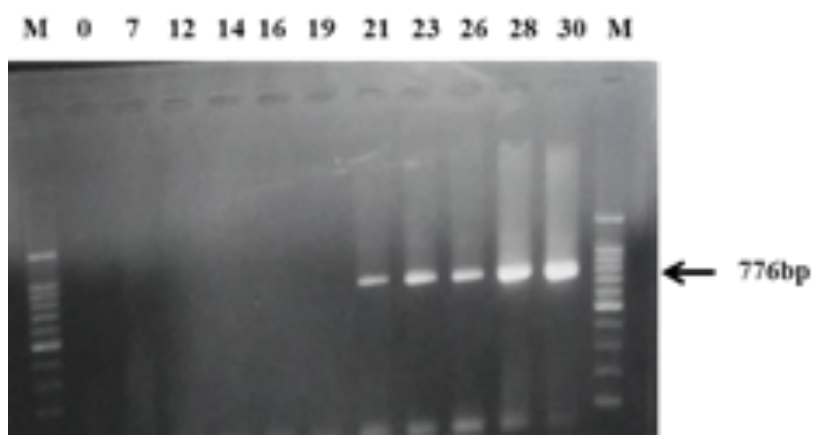

Figure 10. \#8003. PCR detection of $T$. orientalis . M, 100-bp DNA marker, 0-before the inoculation days $7,12,14,16,21,23,28$ and 30 -after inoculation day

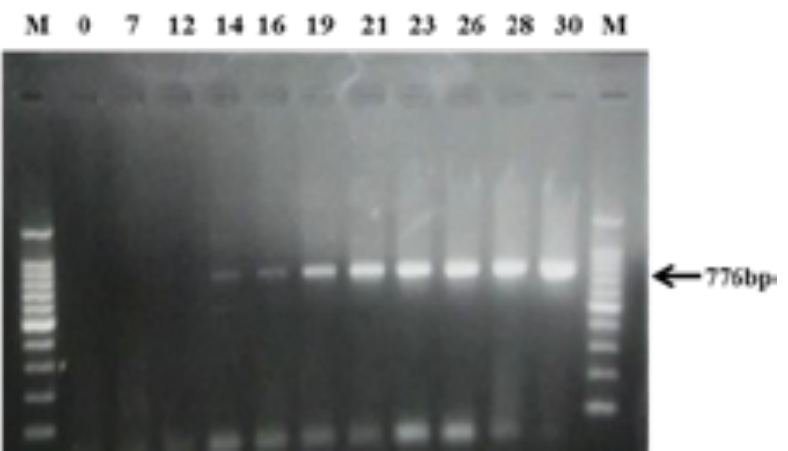

Figure 12. \#8005. PCR detection

T. orientalis. M, 100-bp DNA marker, 0before the inoculation days $7,12,14,16$, $21,23,28$ and 30-after inoculation day after inoculation respectively (Figure 10, 11, 12 and 13).

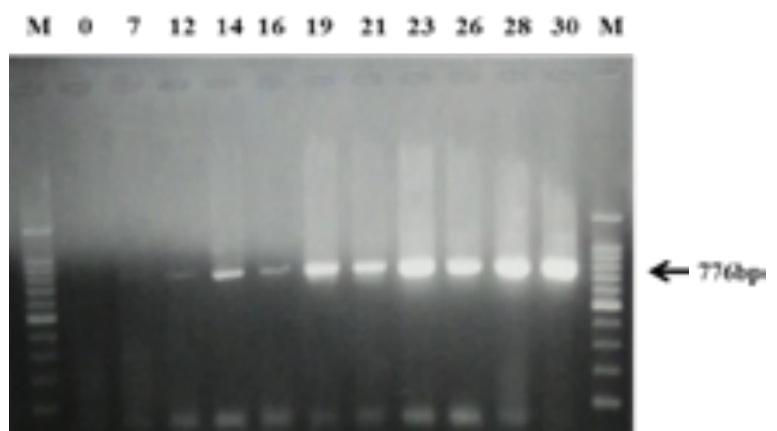

Figure 11. \#8004. PCR detection of $T$. orientalis. M, 100-bp DNA marker, 0before the inoculation day, $7,12,14,16,21$, 23, 28 and 30-after inoculation day

$\begin{array}{lllllllllllll}\mathrm{M} & 0 & 7 & 12 & 14 & 16 & 19 & 21 & 23 & 26 & 28 & 30 & \mathrm{M}\end{array}$

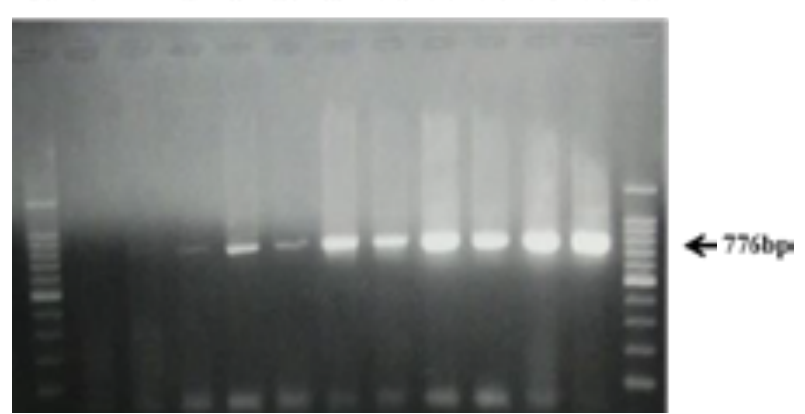

Figure 13. \#8006. PCR detection

T. orientalis. M, 100-bp DNA marker, 0before the inoculation days $7,12,14,16$, 21, 23, 28 and 30-after inoculation day 
The acute infection: PCR analyses could detect the parasite in 3 days after inoculation (Figure 14)

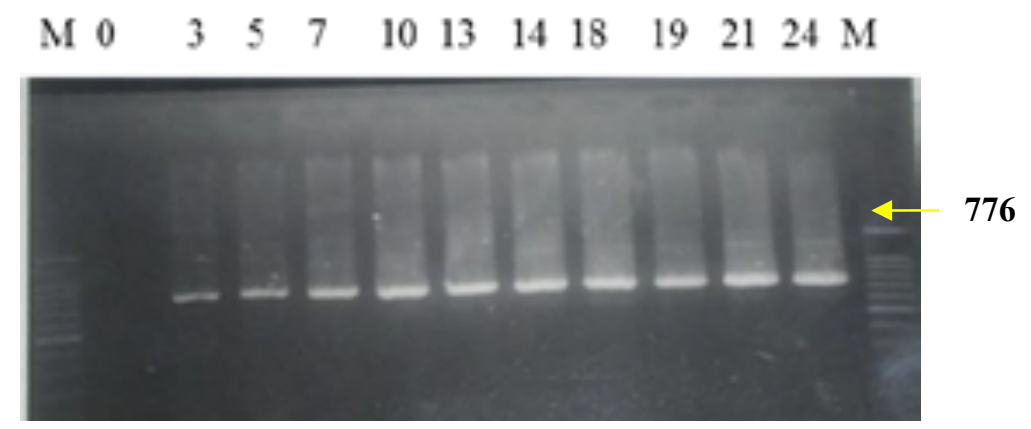

Figure 14. \#8006. PCR detection of T. orientalis.M, 100-bp DNA marker, 0-before the inoculation days $7,12,14,16,21,23,28$ and 30-after inoculation day

Overall, the results showed that all samples were negative for $T$. orientalis before the inoculation of parasite. All animals had hematocritic values (HCT) of over $24 \%$ and $\mathrm{RBC}$ count was rated as free from anemia. After parasite infection, RBC lysis and reduced in number the concentration of $\mathrm{RBC}$ in plasma also reduced. When the RBC count decline so the concentrated HCT also diluted. HCT result showed the similar pattern of the RBC count, but the opposite pattern in parasitemia concentration. During the study parasitemia was developed no intensive. The PCR results were positive in at 7-16 days and 3 days after infection with low dose and high dose of parasite, respectively in all samples after inoculation of $T$. orientalis. In conclusion, this study demonstrates evaluation of hemoparasite infection in the cattle using different kind of laboratory tests such us blood smear test, blood cell examination test and conventional PCR. The blood smear test is still one of easiest, effective diagnostic methods. According to our study results the sensitivity of this test was the same as PCR detection of parasites. We suggest this study design to researchers to know about blood cell structure and real parasite count and estimation, course of anemic stage through the infection and also we can get information about immune response.

\section{REFERENCES}

[1] Kuboto., S., Sugimoto,C., Onuma , M., A genetoic analysis of mixed population in Theileria sergenti stocks and isolates using allele-specific polymerase chain reaction. Journal of Veterinary Medical Science., 57. 279-282, 1995.

[2] Naomi Ota, Daisuke Mizuno, Noritaka Kuboki, Ikuo Igarashi, Yukio Nakamura, Hidenari Ymashina, Teruko Hanzaike, Kei Fuji, Sadao Onoe, Hiroshi Hata, Seiji Kondo, Shirou Matsui, Masao Koga, Kotaro Mashumoto, Hisahi Inokuma, Naoki Yokoyama., Epidemiological survey of Theileria orientalis infection in grazing
Cattle in the Eastern part of Hokkaido, Japan. Parasitology. 937-944, 2009.

[3] Savini. G., Gonte, A .,Semproni.G., Scaramozzino. P., Tick borne diseases in ruminants of Central and southern Italy epidemiology and case reports. Parasitology. 1: 95-100, 1999.

[4] David Menya, AjiNiasono, Yoshio Nakamura., Evaluation of MPSP PCR and application of FTA ${ }^{\mathrm{R}}$ card system in detection of Theileria orientalis infection in Japan. The $66^{\text {th }}$ Wednesday Conference, 2010. 